\section{Gategory}

Metal-Catalyzed Asymmetric Synthesis and Stereoselective Reactions

\section{Key words}

gold catalysis

oxidative rearrangement oxonium ylides
M. XU, T.-T. REN, C.-Y. LI* (ZHEJIANG SCI-TECH UNIVERSITY, HANGZHOU,

P. R. OF CHINA)

Gold-Catalyzed Oxidative Rearrangement of Homopropargylic Ether via Oxonium Ylide

Org. Lett. 2012, 14, 4902-4905.

\title{
Homopropargylic Ether Rearrangement via Gold Catalysis
}
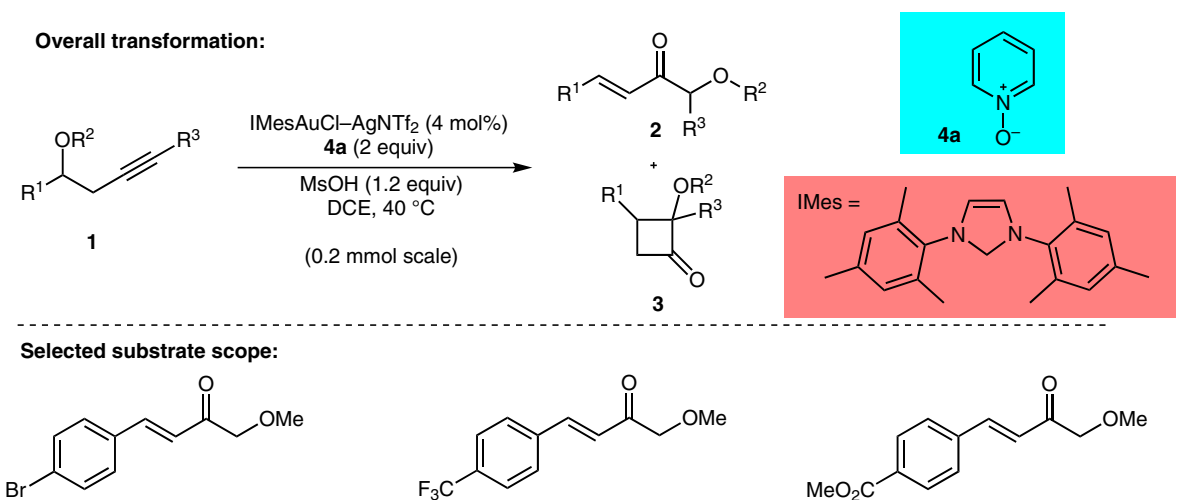

2a $3 \mathrm{~h}, 60 \%$ yield<smiles>COCC(=O)/C=C/c1ccc(C(F)(F)F)cc1</smiles><smiles>CCOC(=O)/C=C/c1ccc(OC)cc1</smiles><smiles>O=C(C=Cc1ccccc1)CO</smiles><smiles>CCCC=CC(=O)COC</smiles>

$2 \mathrm{~d} 2.5 \mathrm{~h}, 64 \%$ yield

2e $9 \mathrm{~h}, 28 \%$ yield<smiles>COCC(=O)/C=C/c1ccco1</smiles>

2f $10 \mathrm{~h}, 0 \%$ yield

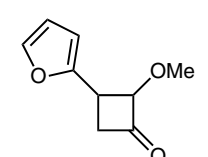

3f $45 \%$ yield (cis observed)

Proposed mechanism:

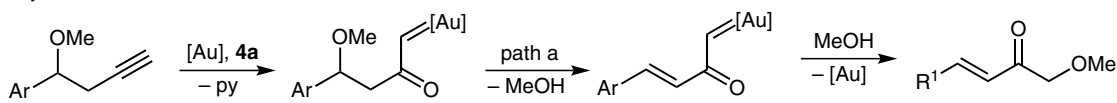

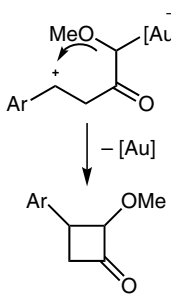<smiles>CC1CCCCC1C</smiles>

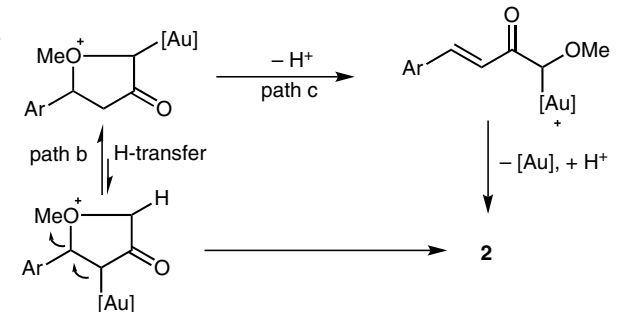

Significance: Gold catalysis has emerged as a powerful platform to conduct complex organic transformations. Specifically, the implementation of gold carbenoids has shown great promise in synthetic planning. These useful intermediates offer a convenient alternative to generate metal carbenes which are traditionally obtained from diazo compounds. The authors utilize these intermediates to synthesize $\alpha, \beta$-unsaturated carbonyl compounds from homopropargylic ethers.

SYNFACTS Contributors: Mark Lautens, David A. Petrone Synfacts 2013, 9(1), 0060 Published online: 17.12.2012 Dol: 10.1055/s-0032-1317758; Reg-No.: L16012SF
Comment: The authors report a silver-assisted gold(I)-catalyzed carbonyl synthesis. In an effort to obtain cyclobutanes $\mathbf{3}$ via a [1,2]-shift mechanism (path d), the authors unexpectingly obtained the corresponding $\alpha, \beta$-unsaturated carbonyl compounds 2. Control experiments show that neither IMesAuCl, nor AgNTf 2 or $\mathrm{HNTf}_{2}$ alone could catalyze the reaction. The scope of the reported reaction is quite broad; however, yields are generally moderate to good. In some instances cyclobutanones are obtained as the major product. 